\title{
Digital educational resources for English language studies: teachers and learners' attitude
}

\author{
Elena Zakirova ${ }^{1, *}$, Elena Kulikova $^{2}$, and Ekaterina Medvedeva ${ }^{3}$ \\ ${ }^{1}$ Moscow State Linguistic University, Moscow, Russia \\ ${ }^{2}$ A.N. Kosygin State University of Russia, Moscow, Russia \\ ${ }^{3}$ National Research University Higher School of Economics (HSE University), Moscow, Russia
}

\begin{abstract}
The introduction of electronic educational content optimizes and facilitates the learning process. This attitudinal study aims to investigate the relation of English teachers and students of the Russian universities (pointed out below) towards digital educational recourses and their usage in the context of foreign language learning. In general, it enables the authors to gather the information about popularity of digital educational recourses for English language learning in order to identify: 1) for what purposes and which digital education recourses are mainly used by English language teachers and whether they manage to achieve the planned result; 2) which resources are of the students' greatest interest and what is the base of their choice; 3 ) weather the students are satisfied with the introduction of digital education recourses in the educational process in general and in the ELT in particular. The study is based on the analysis of the results of the questioning. Participants of the study were school and university teachers and students from Universities of Moscow and Moscow region. The findings of the study showed that there is no significant difference between educators and students' attitudes towards digital education resources. The most participants both teachers and students consider them increasing the effectiveness of learning English. Some of the recourses are popular with both groups of respondents while others have been adopted by one group and easy accessed to the process of language learning.
\end{abstract}

\section{Introduction}

It should be emphasized that digital learning is becoming an increasingly popular option in modern education and particularly in a pandemic Covid 19. The modern educational process is mainly focused both on the use of pedagogical methods and technological achievements. In particular, the use of electronic resources, the information environment, electronic documentation, computer testing, and distance learning has become normal for a modern university. Thus, education is approaching the world in which the modern young generation organically exists [1].

English language teaching being constantly evolved, every decade a new approach or methodology comes into its practice. Nowadays most linguists consider that «a modern

\footnotetext{
* Corresponding author: elena@kulikova.pp.ru
} 
teacher is forced to live in the conditions of an emerging and transforming digital environment, regardless of his own interests, desires and needs» [2]

Most English teachers are ready to practice different educational technologies to perfect their academic and professional experience.

The digitalization of education has been thoroughly studied by the researchers in its general approach [3-4] as well as in English Language Teaching in particular [5-8].

It should be noted that the lack of research works dealing with the study of teachersstudents' attitude to available Digital Educational resources being applied effectively in English language learning. The authors of this article consider the relevance of this research is determined with the need for implementation the most effective digital educational resources in the educational process and to help students master the foreign language within the shortest period of time. The main task of teachers is to show the students the advantages of electronic educational resources and the right ways of their choice and application in the process of English language learning.

\section{Research methodology}

In this research such methods as observation, analysis, interview, survey have been used in order to reveal: 1) the most popular digital educational recourses; 2) the main purposes of their usage by English language teachers; 3) the results which the students can achieve; 4) teachers' / students' satisfaction with the introducing the digital educational recourses in the educational process in general and in the teaching of a foreign language in particular; 5) which digital educational recourses are of the students' greatest interest; 6) what is the base for their choice. The survey method is considered to be the most appropriate one since it allows to get feedback from real users for whom such resources were created.

When contacting the colleagues from different universities and schools the authors of the article have found out that many teachers nowadays widely use the newest and most useful online tools to advance their classroom environment and make their teaching activity and contact with students easier, funny and more interesting. Incorporating digital technology to educational process has changed the teaching strategies of teachers for the better. It should be noted that there are a great number of online programs for ELT. How can teacher or an English learner find the most useful of them. The research is purposed in what teachers should do to choose and why they make this or that choice. Thus, the methods of survey and interview including the questionnaires have been used to evaluate the participants' satisfaction with the existing digital recourses in ELT. To identify the degree of effectiveness of a particular application or website a written questionnaire was completed by the teachers and the students.

The questionnaire involved the selection of educational recourses on the base of the participant's individual judgment, his or her personal experience in the field of foreign language studying.

The authors of the article have tried to reveal the difficulties the teachers can meet. Typically, the teachers should realize the concept of the digital educational recourses under which is commonly understood a set of software, information, technical and organizational support, that reflects a certain subject area and implements the technology for its study by different learning activities. The digital educational recourses can include video material, static and dynamic models, role-playing, objects of virtual reality and interactive modeling, maps, sound recordings, symbolic objects and business graphics, text documents and other educational materials The given educational resources can be presented on a CD, DVD or any other electronic medium, as well as placed on the Internet. It should be noted that digital educational resources have been studied in many researches works [9]. 
In our research work the main method is based on questionnaire survey of school teachers of English, ELT educators and students of the Kosygin Russian State University, Moscow State Linguistic University, Moscow Polytechnic University, Higher School of Economics, Lomonosov Moscow State University, Sechenov University and other Moscow universities, as well as the participants of groups for English teachers in the VK social network.

In the first part of the questionnaire, the teachers needed to name the university or school in which they teach English language at the present time, their age, and gender. In the second part of the questionnaire they were asked the following questions:

1. Do you use any digital educational recourses in your ELT class?

2 Did you turn more to electronic resources during the forced transition to distance learning during the pandemic of Covid-19?

3. Could you list the digital educational recourses you use in your ELT classes and rank them from more frequently used to less used?

4. What resources do you recommend your students for self-study?

5. Are you satisfied with the effectiveness of the use of electronic educational resources?

6 . What are you missing in the existing recourses? What would you like to be improved?

The participants of the survey were also invited to write their opinion on the usage of digital educational recourses in educational process in general and in ELT in particular.

The students of above mentioned Moscow universities were also asked to fill in a questionnaire to assess the effectiveness of modern digital educational recourses.

In the first part of the questionnaire they were asked to indicate the name of the university and the faculty, as well as the year of studying at the university (the course in which the student is studying), the acquired language level in this course (A1, A2, B1, B2, and C1), his or her age and gender. In the second part of the questionnaire, the students were asked to express their opinion on the following questions.

1. Are digital educational recourses used in the ELT classes in your university?

2. Have you been recommended any electronic resources or mobile applications for selfstudying? (which ones?)

3. Which ELT digital educational recourses do you like the most?

4. How do you assess the effectiveness of the use of digital educational recourses in the classroom and for individual work?

They were proposed to evaluate the effectiveness of websites and applications being listed in the previous point. The assessment was made on a scale from 5 points to 0 point, where:

5 - method of a very high efficiency;

4- method of high efficiency;

3 - method of average efficiency;

2 - method of low efficiency;

1 - method of very low efficiency;

0 - an inefficient method

5. Do you use digital educational recourses for self-education?

6. Do you plan to use digital educational recourses when you graduate from the university English course?

The survey was carried out anonymously.

\section{Results}

Totally, 268 teachers from several leading universities in Russia, schoolteachers from Moscow and Moscow region and teachers - participants of groups for ELT educators in social networks (VK and FB) took part in questioning by filling in google question form. Among the teachers (268) taking part in this study 182 were female and 86 were male. Their ages 
ranged between 26 and 62 (with an average of 34 years old). All the participants can be divided into 2 groups: schoolteachers (146), university lectures (122).

1. The majority of respondents $(87 \%)$ confirmed that they used digital educational recourses in their ELT class.

2. More than half $(65 \%)$ of respondents confirmed, that they started or became more active in the use of digital educational recourses while working remotely. This fact is explained with 1) teachers' need for searching the useful resources; 2) teachers' having a constant access to the computer and the Internet (not all classrooms are equipped properly); 3) teachers' realizing that online lessons are different from the usual face-to-face class; 4) teachers' wishes in pandemic situation to facilitate students ' learning activity, to make the lesson more enjoyable (more effort is needed to keep the students ' attention).

3. Respondents were invited to select any number of electronic educational resources and rank them from more frequently used to less frequently used. The teachers pointed out the following electronic educational resources and applications:

- onestopenglish.ccm

- myenglishlab.pearson-intl.com

- learningapps.org

- Quizlet

- Freerice

- Memrise

- Vocabulary.com (mostly be university teachers)

- lingualeo.com

- puzzle-english.com

- puzzle-moviies.com

- elllo.org

- Islcollective.com

- wordwall.net

- dreamreader.net

- English-attack.com

- lyricstraining.com (schoolteachers)

- gamestolearnenglish.com (schoolteachers)

- lifeworksheets.com

- wiser.me

- vznaniya.ru

Having analyzed the participants' questionnaires, it became obviously which recourses are more or less popular. 
Table 1. The results of ranking the electronic educational resources and application.

\begin{tabular}{|c|c|}
\hline $\begin{array}{l}\text { The electronic educational } \\
\text { resources and application }\end{array}$ & $\begin{array}{l}\text { The quantity of teachers } \\
\text { that frequently use it in their practice }\end{array}$ \\
\hline onestopenglish.ccm & $80 \%$ \\
\hline myenglishlab.pearson-intl.com & $85 \%$ \\
\hline learnenglish.britishcouncil.org & $74 \%$ \\
\hline learningapps.org & $82 \%$ \\
\hline Quizlet & $85 \%$ \\
\hline http://dreamreader.net & $62 \%$ \\
\hline Freerice & $75 \%$ \\
\hline Memrise & $80 \%$ \\
\hline Duolingo & $74 \%$ \\
\hline lingualeo.com & $53 \%$ \\
\hline https://puzzle-english.com & $47 \%$ \\
\hline puzzle-moviies.com & $34 \%$ \\
\hline elllo.org & $21 \%$ \\
\hline easytestgenerator.com & $15 \%$ \\
\hline Islcollective.com & $15 \%$ \\
\hline wordwall.net & $15 \%$ \\
\hline wiser.me & $15 \%$ \\
\hline lifeworksheets.com & $10 \%$ \\
\hline English-attack.com & $10 \%$ \\
\hline $\begin{array}{l}\text { www.gamestolearnenglish.com } \\
\text { (schoolteachers) }\end{array}$ & $10 \%$ \\
\hline lyricstraining.com & $10 \%$ \\
\hline vznaniya.ru & $10 \%$ \\
\hline others & less than $5 \%$ \\
\hline
\end{tabular}

The first positions are occupied by websites and applications where teachers can find materials and videos for their classes both at schools and universities. The second position comprises the applications for vocabulary development based on gamification methods and spaced repetition learning technique. Some recourses are popular with university or schoolteachers only.

The teachers often recommend their students for their self-study the following recourses:

- Quizlet (85\%)

- Freerice $(60 \%)$

- Memrise $(72 \%)$

- Duolingo (45\%)

- https://puzzle-english.com (65\%)

- puzzle-moviies.com $(60 \%)$

It should be noted that $70 \%$ respondents are satisfied with the effectiveness of the use of electronic educational resources.

Most respondents (65\%) ignored the question «what would you like to be improved in the recourses you use». Some of the respondents noticed that they would like to have an option using the sources offline and some participants of the survey mentioned that the recourses created by other teachers and shared with teaching community sometimes contain the different mistakes.

In this research 322 students took part: among them were 184 female and 138 males. Generally, they are the students of the following faculties: 
the Faculty of Linguistics (12\%); the Faculty of Art History (10\%); the Faculty of Management (24\%); the Faculty of Education (20\%); the Faculty of Software Engineering and digital technology (34\%).

More than 50\% students answered that digital educational recourses are regularly used in the ELT classes in their universities. Moreover, the students mentioned the following digital educational recourses being used and recommended by their teachers:

- Quizlet

- Freerice

- Memrise

- lingualeo

- puzzle-Englis

- English attack

The students identified the most favorite digital educational recourses. These are the following:

- YouTube channels for learning English (87\%)

- Duolingo (85\%)

- Quizlet (85\%)

- Freerice $(78 \%)$

- Memrise (76\%)

- puzzle-moviies.com (63\%)

- lingualeo $(62 \%)$

- BBC languages (52\%)

- Conversation Exchange (42\%)

- Drops $(42 \%)$

- FluentU (30\%)

Having analyzed the results of students' preferences we can conclude that the students prefer mobile applications and they use educational recourses mainly for communication with native speakers, improving vocabulary and listening skills by watching videos and doing special exercises

It should be noted that the majority of the students-respondents (90\%) assessed the used digital educational recourses as of high rating effectiveness and of very high rating effectiveness. Moreover, $75 \%$ of the students confirmed that they use digital educational recourses for self-education. About $85 \%$ of the respondents are sure they will use digital educational recourses after the graduating from the University.

\section{Discussion}

As the study showed both teachers and students highly appreciated the effectiveness of the use of digital educational recourses. This is also confirmed by the study of Bilalova D. N. Kireeva N. A. Levina T. M. Zharinov Yu. A. Ujmanova I. P. who stated that the increasing use of information and communication technologies has led to changes in teaching and learning at all levels of the higher education system, which has led to an increase in their quality. The methods of classroom learning, and online learning run in parallel and act as a support system for each other» [ibid] As it has already been mentioned above). The effectiveness has been also proved by research work by B. Klimova. There are a lot of Digital Education recourses and Tools one can easily find both for teaching and learning English, this made it possible to develop new competences. The use of mobile applications in developing reading comprehension in second language acquisition. Despite the methodological differences, the findings of all of the identified in two databases: Web of Science and Scopus studies showed that there was an improvement in reading comprehension 
after the treatment with mobile applications. In addition, a positive attitude was determined and enhanced learner motivation when using mobile apps was found in several studies [10]. Nevertheless, a great number of school teachers and university lectures are skeptical about introducing digital educational applications and they prefer not to use the educational means in their English classes. No doubt, technology will always be criticized. As the disadvantages of using electronic devices, many teachers believe that long-term work at computers is harmful to the health of students and a book is much more useful in this regard.

It has been found out that a number of teachers object to the use of electronic resources in principle. Some of them consider the old established methods to be the most effective. They have been looking forward to the abolition of lockdown since they do not know about the existing of such resources. Most teachers and lecturers see the goal of using the digital educational recourses and applications in facilitation. They believe that it is easier to learn words, it is easier to prepare for listening comprehension, it is easier to read. Many teachers noted that automatic verification is the main advantage of electronic resources: this frees up both teachers' time and lesson time.

The authors of the article consider that by means of digital educational resources students are trained more effectively practicing such most popular methods as the discussion and the round table and others. We agree with the researchers' opinion that «the discussion and the round table as teaching methods are the simplest from the point of view of their organization and implementation at the classes, which allow discussing various aspects of future professional activity in a foreign language [11].

Many teachers noted the relevance of electronic resources in comparison with textbooks, the ability to respond to events taking place in the world while learning English.

The significance of using the digital educational recourses was noted by teachers of English for special purposes. We fully agree with the opinion of Vakula E. A. and Kuznetsova M. V who consider that «the developed methods of teaching foreign languages are not sufficiently focused on the age of students, their social and professional status» [12]. Professional vocabulary and texts in the students books quickly become outdated. It is important to teach students to find information in the Internet. Various technologies: video resources, virtual tours, and electronic databases should be introduced in the educational process [13].

It is important for many teachers to be able to create their own electronic resources matching their goals at the particular lesson.

It is popular to create the E-books among schoolteachers, while university teachers hardly use this method.

Some of the teachers use electronic resources only to create tests, since electronic tests are more suitable than the paper ones (video clips can be inserted, it is possible to mix questions ets.).

The school teachers note that the digital educational recourses should not be the main part of education, but should only be additional means and facilitate the educational process. They prefer to leave more time for live communication and discussions.

The resources loved by teachers and students are the same. It can be explained with the fact that the students mostly use the resources on teacher's recommendation. Although many students noted that teachers do not use themselves and do not recommend electronic educational resources to students. The students often follow the recommendations of other students and Internet bloggers. The teachers themselves often learn about interesting resources from colleagues, at specialized training webinars and conferences, as well as in groups and communities for English teachers on social networks.

Many teachers often choose Russian resources since they know more about them, and satisfy the needs of the Russian students. 
Despite the list of useful resources enumerate more than 500 cites, teachers and students use only 15-20 of them. It is quite clear, since many resources are aimed at solving of the same problem and it is easy to choose which is better. Sometimes much time can be spent on resource selection.

Many schoolteachers note that the use of electronic resources makes them feel that the students like the lesson. They say that children are actually very grateful. If they see that the teacher has tried and done something unusual and interesting at the lesson, then they appreciate it. Then they tell their parents what an interesting lesson they had.

The teachers and students emphasize that the using of electronic educational resources allows them to feel surely in people's communication and in the society.

Nowadays the Russian universities implement Moodle as the essential basic pedagogical platform for all kinds of work (materials presentation, attendance monitoring, testing, etc.). Most professors prefer to use the following other means of education such as the following: social media (to place their materials at the personal profile or at a community created especially for each course taught); messengers (to quickly contact people, to reply the requests, to answer questions); E-mail (to contact students group, to send them the necessary information and web links; Video conferencing platforms (Zoom, Discord, MS Teams, TrueConf, and Hangouts for small groups of less than 10 persons).

There exist some testing functions within MS Teams and Moodle, but also specific means such as Google Forms or Typeform and Menti for urgent replying: it helps to collect current opinions simultaneously with the lecture, its implementation usually aims to involve students more than to control or test their knowledge) [14]. These findings have been confirmed by most respondents. Nevertheless, there is a great number of special e-learning tools and applications designed for ELT. The obtained results demonstrate the clear preference for the such digital educational recourses as Quizlet, myenglishlab.pearson-intl.com, learningapps.org, Freerice, Memrise, Vocabulary.com (mostly for the university teachers), lingualeo.com, elllo.org, wordwall.net, puzzle-nglish.com and puzzle-moviies.com.

It should be noted that most university and schoolteachers chose the platforms and resources that facilitate their work and still maintain the high quality of the classes.

It is known that MyEnglishLab can be integrated with systems like Moodle. This system makes easier to see how students are working either individually or as a group, or in comparison with one another. The teacher can also assess the students' activity at every stage: time on task, the number of attempts to get an answer. The most important thing is that all the grammar tasks are checked automatically: it on one hand helps to save teacher's time and on the other hand to free time for more communication and discussions during the lessons. One more significant point is the task made by professional educators and native speakers are always correct. Such International companies as Pearson PLC, Macmillan Education and Oxford University Press and some others that specialized on publishing coursebooks for learning English are quite active and provide educators with all sort of information about their products: they arrange webinars, master classes, conferences etc. That makes their product rather popular among teachers and learners.

As shown by the study, most teachers use websites in their work to make memorizing words more effective. This explains why such resources as Freerice and quizlet occupy a leading position among both teachers and students who took part in the survey.

Most of these sites are based on the method of gamification. The site Freerice can be called as an element of gamification. This site in addition to the elements of gamification, also offers an educational method. (The essence is in the so-called "reward": for each correct answer the student "earns" 10 grains of rice. At the end of the game, the sponsors of the site convert the amount of earned grains into monetary equivalent and transfer this amount of funds to the account of the World Food Program - the largest organization providing humanitarian aid to the hungry. 
The motto of the site is "Play and feed hungry people". Moreover, this resource is largely focused on memorizing synonyms, which is very important in preparing for the Russian and international exams and perfecting the student's speech. There exist the resources that, in addition to gamification elements, are based on interval repetition techniques.

The other most popular recourses are those that help in developing of listening skills. The problem of understanding native speakers' speech is still the main problem of Russian students in learning English. Improvement of listening skills, which are advisable to enhance and to advance in the framework of independent work of students and for which it is impossible to do without electronic resources [15].

We should note that the students who prefer to learn English from authentic videos often use such resources as Puzzle English, Ello, English attacks and others which are very effective. We agree with researchers' opinion that «short video often refers to "snackable content" - a web material that is easy to get and share. Snaps are individual photos or videos. But laid out one by one, for example, photo plus video, they turn into whole stories - a chronological record of the day. Using this technology, it is possible to develop grammatical skill by introducing and fixing any kinds of tense forms of verbs using the video» [16].

Turkish researchers [17] investigated the attitude of students in higher education towards smart phone using in the context of foreign language learning. It is interesting to compare their results with the results of our research.

Having studied the experience of Turkish teachers, it has been founded out that the students mostly used Tureng, Quizlet, TED, Sesli Sözlük (an online dictionary website designed in Turkey) and Google Translate. In addition to them, Oxford Dictionary, British Council, Memrise and Cambridge Dictionary websites were used most by prep-school students. These results can be interpreted as students using their mobile devices to look up the meaning of English words most of the time during their exposure to language learning while the Russsian students put Quizlet on the first place, but the list are different. Many Russian students have chosen the same vocabulary resources as Turkish. However, the difference is that Russian students prefer Russian recourses, which are probably more in line with the needs of Russian-speaking English learners, while Turkish students prefer the Turkish sites. Moreover, Russian students did not mention online dictionaries, perhaps simply not considering them as digital educational recourses.

It is known that such recourses as Zoom, Google meets, Skype and other platforms have been widely used for conducting classes, conferences in pandemic COVID-19 circumstances. For example, the A.N. Kosygin University used this opportunity to hold a poetry festival in the studied languages together with a Turkish University, making its contribution to strengthening cooperation, intercultural communication and acquaintance with the best examples of poetry in different languages.

It is also worth paying attention to the time that students spend on the online part of their learning. Most of them spent less time than the recommended for the language courses. This undoubtedly identifies the problem which is of great interest for future research. It also points to the problem for course developers and teachers [18]

\section{Conclusions}

Analysis result showed that there is no significant difference between educators and students' attitudes towards digital education resources. Both teachers and students agree that they increase the effectiveness of learning English. Some of the recourses are popular with both groups of respondents while others are useful just for one group (either for teachers or for students). Despite the fact that many researchers claim that teachers' competency in the use of technology is still problematic, most teachers are willing to use digital education recourses.

Some educational recourses are more popular with teachers and students - Quizlet 
Memrise, lingualeo.com, puzzle-english.com - it is probably due to their proved effectiveness while others, for example, English attack, that provides an unique and really useful content got only $10 \%$ of respondents assessment. Probably it can be explained by the lack of advertisement because of its high price.

The achievement of high educational results becomes possible due to the implementation of the main functions of digital educational resources, which include the initiation of new types of educational activities and support for the functioning of traditional types of educational activities at a higher quality level. The digital educational resources are proposed to be considered as an addition to the traditional face-to-face work of the teacher and the student.

Some critics believe that such technologies reduce practice experience and student's engagement in active participation in educational process. Moreover, the technology are supposed to reduce important human contact. It is evidenced that the using of information technologies in English language teaching facilitate the teacher's routine work and give more communication opportunities, encouraging more teacher-student and student-student discussion.

The authors of the article express their gratitude to the reviewers for the analysis of the presented work, students and teachers who took part in the study.

\section{References}

1. G.V. Varakina, Modern technologies in science and education-STNO-2019. Proceedings of the II International Scientific and Technical Forum: in 10 volumes, 204 (2019)

2. O.N. Griban, 1st International Scientific Conference "Modern Management Trends and the Digital Economy: from Regional Development to Global Economic Growth" (MTDE 2019)

3. C.R. Jiménez, Education Sciences 9(3), 169 (2019)

4. N. Almazova, E. Krylova, A. Rubtsova, M. Odinokaya, Education Sciences 10(12), 1 (2020)

5. J. Kacetl, B. Klímová, Educ. Sci. 9, 179 (2019)

6. T.T. Wu, Y.M. Huang, Educ. Technol. Soc. 20, 265 (2017)

7. K. Kapranchikova, Language and Culture, 1 (2014)

8, I.H. Taj, A. Fatimah, S. Muhammad, A. Waqar, Arab. World Engl. J. 8, 108 (2020)

9. D. N. Bilalova, N. A. Kireeva, T. M. Levina, DETP 2020, 315 (2020)

10. B. Klimova, Education Sciences 10(12), 1 (2020)

11. I.G. Belyaeva, E.A. Samorodova, O.V. Voron, E.S. Zakirova, Education Sciences 9(3), 171 (2019)

12. E.A. Vakula, M.V. Kuznetsova, Modern science: actual problems of theory and practice. Series: Humanities 4, 117 (2020)

13. G.V. Varakina, E.V. Kulikova, M.V. Yudin, 2020 International Conference on Language, Communication and Culture Studies (ICLCCS 2020)

14. N.N. Pokrovskaia, V.L. Leontyeva, M.Y. Ababkova, L. Cappelli, F. D’Ascenzo, Future Internet 13, 43 (2021)

15. E.V. Kulikova, M.A. Kulikov, Yu. M. Sultanova, Modern trends in the development of continuing education: challenges of the digital economy. International conference, 110 (2020) 
16. O. Anyushenkova, O. Digtyar, E. Zakirova, N. Fomina, L. Esina, Edulearn19 Proceedings, 3428 (2019)

17. C. Yurdagül, S. Öz, Education Sciences 8, 142 (2018)

18. D. Bylieva, V. Lobatyuk, A. Safonova, A. Rubtsova, Education Sciences 9(3), 167 (2019) 